\title{
References
}

1 National Lung Screening Trial Research Team. Reduced lung-cancer mortality with low-dose computed tomographic screening. N Engl J Med 2011; 365: 395-409.

2 de Koning HJ, Meza R, Plevritis SK, et al. Benefits and harms of computed tomography lung cancer screening strategies: a comparative modeling study for the U.S. Preventive Services Task Force. Ann Intern Med 2014; 160: 311-320.

3 Woolf SH, Harris RP, Campos-Outcalt D. Low-dose computed tomography screening for lung cancer: How strong is the evidence? JAMA Intern Med 2014; 174: 2019-2022.

4 Hew M, Stirling RG, Abramson MJ. Should we screen for lung cancer in Australia? Med J Aust 2013; 199: 82-83.

5 Field JK, Smith RA, Aberle DR, et al. International Association for the Study of Lung Cancer computed tomography screening workshop 2011 report. J Thorac Oncol 2012; 7: 10-19.

6 Black WC, Gareen IF, Soneji SS, et al. Cost-effectiveness of CT screening in the national lung screening trial. N Engl J Med 2014; 371: 1793-1802.

7 Marshall HM, Bowman RV, Crossin J, et al. Queensland lung cancer screening study: rationale, design and methods. Int Med J 2013; 43: 174-182.

8 National Lung Screening Trial Research Team. Baseline characteristics of participants in the randomized national lung screening trial. J Natl Cancer Inst 2010; 102: 1771-1779.

9 Lin RT, Takahashi K, Karjalainen A, et al. Ecological association between asbestos-related diseases and historical asbestos consumption: an international analysis. Lancet 2007; 369: 844-849.

10 Park EK, Yates DH, Hyland RA, et al. Asbestos exposure during home renovation in New South Wales. Med J Aust 2013; 199: 410-413.

11 Queensland Government. Asbestos investigation - former plants. www.health.qld.gov.au/asbestos Date last accessed: February, 2015. Date last updated: February 19, 2015.

12 The National Lung Screening Trial Research Team. Results of initial low-dose computed tomographic screening for lung cancer. N Engl J Med 2013; 368: 1980-1991.

13 Aberle DR, DeMello S, Berg CD, et al. Results of the two incidence screenings in the National Lung Screening Trial. N Engl J Med 2013; 369: 920-931.

14 Horeweg N, van der Aalst CM, Vliegenthart R, et al. Volumetric computed tomography screening for lung cancer: three rounds of the NELSON trial. Eur Respir J 2013; 42: 1659-1667.

15 Ferlay J, Soerjomataram I, Ervik M, et al. GLOBOCAN 2012 v1.0, Cancer Incidence and Mortality Worldwide: IARC CancerBase No. 11. http://globocan.iarc.fr Date last accessed: May, 2014.

16 Tammemägi MC, Katki HA, Hocking WG, et al. Selection criteria for lung-cancer screening. N Engl J Med 2013; 368: $728-736$.

\section{Quadriceps muscle fibre dysfunction in patients with pulmonary arterial hypertension}

To the Editor:

Despite improvements in disease targeted therapies, pulmonary arterial hypertension (PAH) is a progressive disease and PAH patients remain symptomatic [1]. Exercise intolerance is one of the main symptoms, which limit PAH patients in their daily life activities. Reduced exercise capacity is generally attributed to right ventricular dysfunction [1]. However, as with other cardiac and pulmonary diseases, PAH patients develop respiratory [2] and peripheral muscle [3,4] weakness, which might also contribute to exercise intolerance. Indeed, exercise training improves exercise capacity in PAH patients and maximal oxygen consumption of PAH patients correlates with the functional decline of peripheral muscle strength $[5,6]$. The underlying cause of the reduction in muscle strength is unclear. Some studies have reported muscle fibre atrophy and a shift towards more fast-twitch fatigable fibres in skeletal muscles of PAH patients [3, 7]; however, these are not consistent findings [4, 8].

Recently, we have shown that weakness of the respiratory muscles in PAH patients [8] and in pulmonary hypertension rats [9] is, at least partly, caused by impaired contractility of the sarcomeres, the smallest contractile units in muscle. Whether sarcomere contractility is also affected in peripheral muscles of PAH patients is yet unknown. Physical activity declines in $\mathrm{PAH}$ patients and muscle disuse is known to affect 
sarcomere function [10]. Therefore, in the present study, we hypothesised that sarcomere contractility is impaired in peripheral muscles of $\mathrm{PAH}$ patients.

To test this hypothesis, we measured sarcomeric function in permeabilised individual muscle fibres of idiopathic PAH patients. In permeabilised muscle fibres, sarcomeric contractility can be studied without the confounding effects of processes upstream in the excitation-contraction coupling cascade. The fibres were isolated from quadriceps muscle (vastus lateralis) biopsies of female $\mathrm{PAH}$ patients $(\mathrm{N}=11)$ and were compared to those from healthy, age- and sex-matched control subjects $(\mathrm{N}=8)$. For patients' characteristics, see figure 1a. All subjects gave written informed consent before inclusion. Ethical approval was given by the institutional review board at VU University Medical Center, Amsterdam, the Netherlands. This report focuses on results obtained on fast-twitch fibres because of the low number of slow-twitch muscle fibres present in the biopsies (PAH: number of patients (Npatients) $=4$, number of fibres (nfibres) $=5$; control: Npatients $=5$, nfibres $=13$ ).

Individual fibres were mounted between a force transducer and servomotor, and exposed to activating calcium solutions, as described previously [9]. Maximal tension (i.e. maximal force normalised to muscle fibre cross-sectional area (CSA)) was significantly lower in fast-twitch muscle fibres of PAH patients (Npatients=11, nfibres=112) than in control subjects (Npatients=8, nfibres=62) (mean \pm SEM $192 \pm 5$ versus $226 \pm 8 \mathrm{mN} \cdot \mathrm{mm}^{-2}, \mathrm{p}<0.005$; fig. $1 \mathrm{~b}$ ). Based on our permeabilised muscle fibre measurements, we observed no significant difference in fast-twitch muscle fibre CSA between groups (PAH versus control: $3387 \pm 280$ versus $3307 \pm 242 \mu \mathrm{m}^{2} ; \mathrm{p}=0.84$ ).

In muscle fibres, force is generated by the cyclic interaction between myosin-based cross-bridges and actin. Thus, to determine the underlying cause of the reduction in maximal tension, we studied cross-bridge cycling kinetics. In permeabilised muscle fibres, active force generation is determined by: 1) the fraction of strongly bound cross-bridges; 2) the number of available cross-bridges; and 3) the force generated per cross-bridge. First, to estimate the fraction of strongly bound cross-bridges we measured the rate constant of force redevelopment (ktr) during maximal activation. No significant difference in ktr was observed in fast-twitch muscle fibres (fig. 1c), suggesting that the fraction of strongly bound cross-bridges was unaltered. Secondly, to estimate the number of available cross-bridges, we measured active stiffness by imposing fast $(<1 \mathrm{~ms})$, small length changes on the fibre during maximal activation. Active stiffness reflects the number of attached cross-bridges during activation, which is determined by both the fraction of strongly bound cross-bridges (ktr) as well as the number of available cross-bridges. We found a significant decrease in active stiffness in fast-twitch muscle fibres of PAH patients (fig. 1d). Since ktr was unaltered, this suggests that the number of available cross-bridges is reduced in quadriceps muscle fibres of PAH patients. Finally, we estimated the force generated per cross-bridge by calculating the tension/ stiffness ratio. No significant difference was observed between groups (fig. 1e), indicating that the force generated per cross-bridge is unaltered.

During daily life activities, quadriceps muscles are generally not maximally activated but activated at submaximal motor neuron firing rates, which yield submaximal calcium concentrations $\left(\left[\mathrm{Ca}^{2+}\right]\right)$. Therefore, we measured force at submaximal $\left[\mathrm{Ca}^{2+}\right]$. The tension- $\left[\mathrm{Ca}^{2+}\right]$ relationship shows that at high $\left[\mathrm{Ca}^{2+}\right]$, tension was significantly lower (fig. 1f). The $\left[\mathrm{Ca}^{2+}\right]$ at which $50 \%$ of the maximal force is reached was unaffected in fast-twitch muscle fibres of PAH patients. Thus, changes in the $\mathrm{Ca}^{2+}$ sensitivity of force do not contribute to contractile muscle fibre weakness in PAH patients.

For optimal active force generation, structural integrity of the sarcomere is indispensable. This structural integrity is regulated by the passive elastic properties of the giant sarcomeric protein titin. Therefore, we measured passive tension in muscle fibres by stretching the fibre from slack length $(\sim 1.9 \mu \mathrm{m})$ to a sarcomere length of $\sim 3.2 \mu \mathrm{m}$ (velocity, $10 \%$ length change per second) while in relaxing solution $\left(\left[\mathrm{Ca}^{2+}\right]\right.$ $1 \mathrm{nM})$. A significant upward shift in passive tension-sarcomere length relationship was observed in fast-twitch muscle fibres (fig. 1g), indicating that the passive tension of quadriceps muscle fibres is increased in PAH patients.

This is the first study to show sarcomeric contractile weakness in the quadriceps muscle of PAH patients. This weakness is caused by a reduction in the number of available cross-bridges, which might result from a loss of the major contractile protein myosin. Notably, the reduction in maximal tension $(\sim 15 \%)$ was less than the reduction in muscle strength measured in vivo (20-30\%) [3], suggesting that extrasarcomeric changes, for example, in the process of excitation-contraction coupling, and/or muscle atrophy also contribute to peripheral muscle weakness.

A limitation of the present study is that our findings are restricted to fast-twitch muscle fibres, whereas the vastus lateralis in humans, including PAH patients, contains $30-40 \%$ slow-twitch fibres [7]. The low number of slow-twitch muscle fibres found in the biopsies might be a result of sampling error. Therefore, 
a)

\begin{tabular}{lcc}
\hline & Control & iPAH \\
\hline Patients & 8 & 11 \\
Age years & $59 \pm 3$ & $58 \pm 15$ \\
NYHA functional class II/III & $7 / 4$ \\
6MWD m & $428 \pm 103$ \\
Cardiac output L-min-1 & $5.0 \pm 1.4$ \\
mPAP mmHg & $43 \pm 16$ \\
NT-proBNP ng.L-1 median & 1340 \\
$\quad$ (range) & $165-9859]$ \\
Therapy\# & \\
$\quad$ Triple & 3 \\
Double & 2 \\
Single & 5 \\
\hline
\end{tabular}

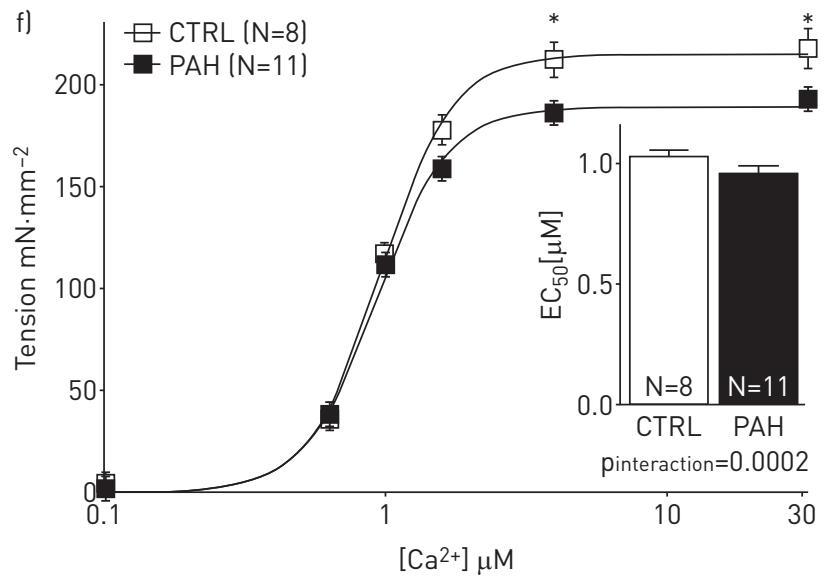

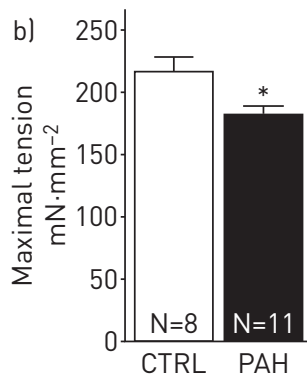
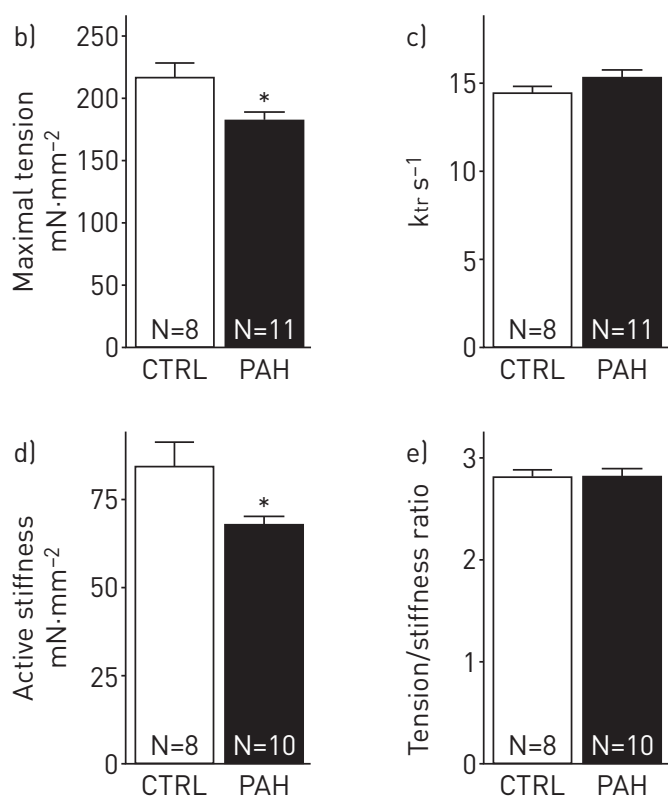

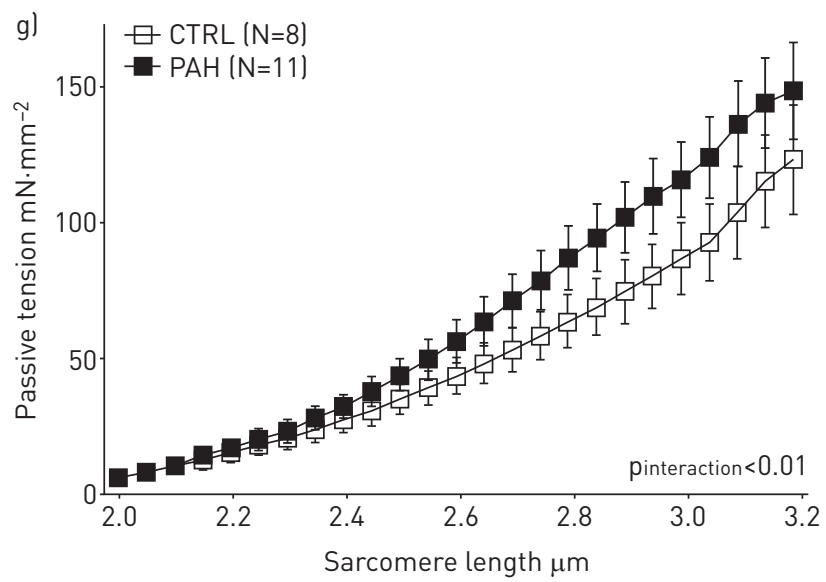

FIGURE 1 a) Patients' characteristics. Data are presented as $n$ or mean \pm SD, unless otherwise stated. iPAH: idiopathic pulmonary arterial hypertension; NYHA: New York Heart Association; 6MWD: 6-min walking distance; mPAP: mean pulmonary artery pressure; NT-proBNP: N-terminal pro-brain natriuretic peptide. \#: therapies consisted of a phosphodiesterase type 5 inhibitor, an endothelin receptor antagonist and/or prostacyclin. b) Maximal tension (i.e. maximal force per $\mathrm{mm}^{2}$ cross sectional area at $20^{\circ} \mathrm{C}$ and a calcium concentration $\left(\left[\mathrm{Ca}^{2+}\right]\right)$ of $\left.32 \mu \mathrm{M}\right)$ is significantly reduced in fast-twitch quadriceps muscle fibres of pulmonary hypertension (PAH) patients compared with age- and sex-matched control subjects (CTRL). c) No change in the rate constant of force redevelopment ( $\mathrm{ktr}$ ) was observed between groups, suggesting that the fraction of strongly bound cross-bridges is unaltered. d) Active stiffness, measured by imposing fast $(<1 \mathrm{~ms})$, small length steps $(0.3-0.9 \%$ of initial length) on the fibre during maximal activation, was significantly lower in fast-twitch muscle fibres of PAH patients than in control subjects, indicating that the number of attached cross-bridges during activation is reduced. e) The tension/stiffness ratio, an estimate of the force per cross-bridge, was not significantly different between groups. $\mathrm{f}$ ) The tension- $\left[\mathrm{Ca}^{2+}\right]$ curve shows that at high $\left[\mathrm{Ca}^{2+}\right]$, tension was significantly lower. However, the $\left[\mathrm{Ca}^{2+}\right]$ at which $50 \%$ of the force is reached (EC50) was not significantly different (inset); thus, Ca ${ }^{2+}$ sensitivity is unaltered. g) A significant upward shift in the passive tension-sarcomere length relationship was observed in PAH patients, suggesting an increase in passive tension in PAH patients. Data are presented as mean \pm SEM. N: number of patients; pinteraction: $\mathrm{p}$-value for interaction. ${ }^{*}$ : $\mathrm{p}<0.05$ versus control.

caution is warranted when extrapolating the current findings to the whole muscle. Measurements were performed shortly after the biopsy was taken to avoid deterioration of muscle fibres over time. The researcher involved in the experiments was also involved in obtaining the biopsies. Therefore, the experiments were not performed blind, which is another limitation of this study.

In addition, we observed that passive tension of quadriceps muscle fibres was increased in PAH patients. This was an unexpected finding, as muscle disuse and loss of myosin are associated with a reduction in passive tension [11]. Passive tension was already increased by $39 \%$ at a sarcomere length of $2.5 \mu \mathrm{m}$, with a more pronounced increase at higher sarcomere lengths. As in vivo, muscle contraction is estimated to occur at a sarcomere length ranging from 2.5 to $3.2 \mu \mathrm{m}$ [12], the increase in passive tension is likely to affect in vivo muscle function. Increased titin-based passive tension is associated with an increase in the $\mathrm{Ca}^{2+}$ sensitivity of force generation, possibly by reducing myofilament lattice spacing [13]. Although 
speculative, the increase in passive tension in $\mathrm{PAH}$ patients might be a compensatory mechanism to maintain $\mathrm{Ca}^{2+}$ sensitivity and, thus, submaximal force generation.

As muscle dysfunction affects exercise capacity and quality of life of PAH patients, therapeutic options that specifically improve skeletal muscle function are warranted. While it is recognised that exercise training can improve muscle function and exercise capacity in PAH patients [5], its tolerability is limited in severely haemodynamically impaired PAH patients [6]. Calcium sensitisers, which specifically target sarcomeric function by improving submaximal force generation and reduced $\left[\mathrm{Ca}^{2+}\right.$ ] pumping by the sarco/endoplasmic reticulum $\mathrm{Ca}^{2+}$ ATPase $[14,15]$, might be a pharmacological therapeutic option to improve muscle function in this patient population.

To conclude, peripheral muscle weakness in PAH patients is at least partly caused by sarcomeric dysfunction. As muscle weakness might contribute to the reduction in exercise capacity, therapeutic options to specifically improve muscle function should be studied. http://ow.ly/J8LuE

Emmy Manders ${ }^{1,2}$, Gerrina Ruiter ${ }^{1}$, Harm-Jan Bogaard ${ }^{1}$, Ger J.M. Stienen ${ }^{2,3}$, Anton Vonk-Noordegraaf ${ }^{1}$, Frances S. de Man ${ }^{1}$ and Coen A.C. Ottenheijm ${ }^{2}$

${ }^{1}$ Dept of Pulmonology, VU University Medical Center, Institute for Cardiovascular Research, Amsterdam, The Netherlands. ${ }^{2}$ Dept of Physiology, VU University Medical Center, Institute for Cardiovascular Research, Amsterdam, The Netherlands. ${ }^{3}$ Dept of Physics and Astronomy, VU University, Amsterdam, The Netherlands.

Correspondence: Coen A.C. Ottenheijm, Dept of Physiology, Institute for Cardiovascular Research, VU University Medical Center, Van der Boechorststraat 7, 1081 BT Amsterdam, The Netherlands. E-mail: c.ottenheijm@vumc.nl

Received: Nov 052014 | Accepted after revision: Jan 302015 | First published online: March 052015

Conflict of interest: Disclosures can be found alongside the online version of this article at erj.ersjournals.com

\section{References}

1 Humbert M, Sitbon O, Chaouat A, et al. Survival in patients with idiopathic, familial, and anorexigen-associated pulmonary arterial hypertension in the modern management era. Circulation 2010; 122: 156-163.

2 Kabitz H-J, Schwoerer A, Bremer H-C, et al. Impairment of respiratory muscle function in pulmonary hypertension. Clin Sci 2008; 114: 165-171.

3 Mainguy V, Maltais FF, Saey D, et al. Peripheral muscle dysfunction in idiopathic pulmonary arterial hypertension. Thorax 2010; 65: 113-117.

4 Potus F, Malenfant S, Graydon C, et al. Impaired angiogenesis and peripheral muscle microcirculation loss contribute to exercise intolerance in pulmonary arterial hypertension. Am J Respir Crit Care Med 2014; 190: 318-328.

5 Mereles D, Elkhen N, Kreuscher S, et al. Exercise and respiratory training improve exercise capacity and quality of life in patients with severe chronic pulmonary hypertension. Circulation 2006; 114: 1482-1489.

6 De Man FS, Handoko ML, Groepenhoff $\mathrm{H}$, et al. Effects of exercise training in patients with idiopathic pulmonary arterial hypertension. Eur Respir J 2009; 34: 669-675.

7 Batt J, Ahmed SS, Correa J, et al. Skeletal muscle dysfunction in idiopathic pulmonary arterial hypertension. Am J Respir Cell Mol Biol 2014; 50: 74-86.

8 De Man FS, van Hees HW, Handoko ML, et al. Diaphragm muscle fiber weakness in pulmonary hypertension. Am J Respir Crit Care Med 2011; 183: 1411-1418.

9 Manders E, de Man FS, Handoko ML, et al. Diaphragm weakness in pulmonary arterial hypertension: role of sarcomeric dysfunction. Am J Physiol Lung Cell Mol Physiol 2012; 303: L1070-L1078.

10 D'Antona G, Pellegrino MA, Adami R, et al. The effect of ageing and immobilization on structure and function of human skeletal muscle fibres. J Physiol 2003; 552: 499-511.

11 Udaka J, Ohmori S, Terui T, et al. Disuse-induced preferential loss of the giant protein titin depresses muscle performance via abnormal sarcomeric organization. J Gen Physiol 2008; 131: 33-41.

12 Llewellyn ME, Barretto RP, Delp SL, et al. Minimally invasive high-speed imaging of sarcomere contractile dynamics in mice and humans. Nature 2008; 454: 784-788.

13 Fukuda $\mathrm{N}, \mathrm{Wu} \mathrm{Y}$, Farman G, et al. Titin-based modulation of active tension and interfilament lattice spacing in skinned rat cardiac muscle. Pflugers Arch 2005; 449: 449-457.

14 Hooijman P, Beishuizen A, de Waard M, et al. Diaphragm fiber strength is reduced in critically ill patients and restored by a troponin activator. Am J Respir Crit Care Med 2014; 7: 863-865.

15 Russell AJ, Hartman JJ, Hinken AC, et al. Activation of fast skeletal muscle troponin as a potential therapeutic approach for treating neuromuscular diseases. Nat Med 2012; 18: 452-455. 